\title{
High Platelet-Lymphocyte Ratio is a Risk Factor for 30-day Mortality In In-Hospital Cardiac Arrest Patients: A Case-Control Study
}

\section{Lihong Huang}

Chongqing Medical University https://orcid.org/0000-0003-1121-4859

Jingjing Peng

The First Affiliated Hospital of Chongqing Medical University

\section{Xuefeng Wang}

The First Affiliated Hospital of Chongqing Medical University

Feng Li (D13752905801@163.com )

The First Affiliated Hospital of Chongqing Medical University

\section{Research}

Keywords: cardiac arrest, post-cardiac arrest syndrome, ROSC, critical care, mortality

Posted Date: May 17th, 2021

DOI: https://doi.org/10.21203/rs.3.rs-516866/v1

License: (a) (i) This work is licensed under a Creative Commons Attribution 4.0 International License. Read Full License 


\section{Abstract}

Background: Early identification of risk factors for short-term mortality in patients with in-hospital cardiac arrest (IHCA) is crucial for early prognostication. This study aimed to explore the association of early dynamic changes in inflammatory markers with 30-day mortality in IHCA patients.

Methods: This study retrospectively collected demographic and clinical characteristics and relevant laboratory indicators within $72 \mathrm{~h}$ after recovery of spontaneous circulation (ROSC) of IHCA patients from December 2015 to December 2020 at the First Affiliated Hospital of Chongqing Medical University. The outcome was 30-day mortality. A linear mixed model was used to analyze the dynamic changes in laboratory indicators within $72 \mathrm{~h}$ after ROSC, and Cox regression was used to identify the independent risk factors for 30-day mortality.

Results: Overall, $85 \mathrm{IHCA}$ patients were included. The $0-72 \mathrm{~h}$ and $0-30$ day cumulative mortality rates were $25.88 \%$ and $57.65 \%$, respectively, and the median survival time was 13.79 days. There was no association of inflammatory markers before IHCA with mortality. Within $72 \mathrm{~h}$ after ROSC, inflammatory markers showed various changes: the absolute monocyte count (AMC) showed no significant change trend, and the absolute lymphocyte count (ALC) showed an overall upward trend, while the absolute neutral count (ANC), white blood cell (WBC) count, platelet (PLT) count, neutrophil-lymphocyte ratio (NLR), platelet-lymphocyte ratio (PLR) and systemic immune-inflammation index (SII) showed an overall downward trend. Cox multivariate analysis showed that Charlson comorbidity index (CCl) $(\mathrm{HR}=2.366$, $95 \% \mathrm{Cl}(1.084,5.168))$, APACHE II score (HR $=2.550,95 \% \mathrm{Cl}(1.001,6.498))$, abnormal $\mathrm{Cr}$ before IHCA (HR $=3.417,95 \% \mathrm{Cl}(1.441,8.104))$ and PLR within $72 \mathrm{~h}$ after $\operatorname{ROSC}(\mathrm{HR}=2.993,95 \% \mathrm{Cl}(1.442,6.214))$ were independent risk factors for 30-day mortality. When PLR $\geq 180$, the risk of 30 -day mortality increased by $199.3 \%$.

Conclusions: This study clarified the dynamic change trends of inflammatory markers within $72 \mathrm{~h}$ after ROSC. The PLR was an independent risk factor for 30-day mortality in IHCA patients; it can be used as a predictor of short-term mortality and provide a reference for early prognostication.

Trial registration: ChiCTR1800014324

\section{Background}

The prognosis of patients with in-hospital cardiac arrest (IHCA) essentially depends on the organization of the chain of survival. With the improvement of cardiopulmonary resuscitation (CPR) quality and the development of advanced life support technology that can be used in the early stage, the successful resuscitation rate of IHCA patients has greatly increased, and the survival time has also been prolonged, but the short-term survival rate has not been significantly improved (only approximately 25\%) [1, 2]. In 2019, JAMA's latest review on IHCA [3] pointed out that two-thirds of patients with out-of-hospital cardiac arrest (OHCA) with successful resuscitation die of neurological causes, while the cause of short-term mortality in IHCA patients is different: in these patients, multiorgan dysfunction drives mortality. 
Therefore, early intervention for organ dysfunction is the first step for reducing multiple organ injury and improving clinical outcomes in IHCA patients [4].

A potential pathological process of early organ failure in IHCA patients is the development of post cardiac arrest syndrome (PCAS) [5]. Four phases are thought to occur in the development of PCAS [6], and the first two stages, which occur $0-72 \mathrm{~h}$ after resuscitation, are the crucial periods that determine the prognosis of patients. During this period, ischemia and hypoxia during cardiac arrest and reperfusion injury after resuscitation lead to comprehensive activation of the immune system and the coagulation pathway [7], which can lead to "sepsis-like syndrome" and eventually to multiorgan dysfunction and even poor prognosis [6, 8]. Sugita et al. [9] further pointed out that the inflammatory response is closely related to reperfusion injury. Prolonged hypoxia can lead to activation of endothelial cells, and comprehensive activation of multiple inflammatory pathways can lead to systemic inflammatory response syndrome, which can eventually lead to multiple organ failure and even death of patients [10]. Therefore, strengthening the monitoring of early inflammatory markers and administering targeted treatment and intervention probably improve the organ function and prognosis of patients [11-13].

This study aims to explore the association of dynamic changes in routine inflammatory markers within $72 \mathrm{~h}$ after recovery of spontaneous circulation (ROSC) with the 30-day mortality of IHCA patients. The goal is to further clarify the immunopathological process of PCAS by understanding the early changes of routine inflammatory markers and to provide promising candidate biomarkers for predicting the 30-day mortality of IHCA patients.

\section{Methods}

\subsection{Study design and participants}

This study was a case-control study. The subjects were patients with IHCA at the First Affiliated Hospital of Chongqing Medical University from December 2015 to December 2020. When an IHCA event occurred, junior residents performed CPR immediately. Experienced senior residents and attendants participated in the following processes, including but not limited to CPR, airway management, vasopressor administration, defibrillation and other advanced resuscitation measures, performed according to the guidelines of advanced cardiac life support (ACLS) [14]. After ROSC, the patient was admitted to the intensive care unit for further treatment. This study was conducted in accordance with the Declaration of Helsinki and approved by the Medical Ethics Committee of the First Affiliated Hospital of Chongqing Medical University.

Inclusion criteria: (1) age $\geq 18$ years old; (2) CPR for at least 5 minutes (this time point was selected given that patients with IHCA undergoing conventional CPR for less than 5 min have a greater than $70 \%$ survival with favorable neurologic outcome) [15]; (3) sustained ROSC; and (4) informed consent form signed by the patient or an authorized family member. Exclusion criteria: (1) incomplete data; (2) withdrawal of treatment immediately after ROSC due to delayed confirmation of do not resuscitate order; 
(3) autoimmune diseases or use of immunosuppressants (such as corticosteroids) in the last 3 months; and (4) major trauma or surgical operation affecting hematological parameters (see Fig. 1).

\subsection{Outcome}

The outcome was 30-day mortality. Survival was censored at 30 days following IHCA, and patients discharged prior to this time point were subsequently contacted by phone to ascertain survival status. The patients were divided into a death group and a survival group.

\subsection{Data collection}

The clinical and laboratory indicators of $85 \mathrm{IHCA}$ patients were collected retrospectively. If a patient had multiple cardiac arrest events during hospitalization, only the first event was recorded [16].

1) Clinical indicators: age, sex, Charlson comorbidity index (CCl), pulmonary infection before cardiac arrest, etiology of IHCA (cardiogenic or noncardiogenic), initial rhythm (e.g., ventricular fibrillation, ventricular tachycardia, asystole, bradycardia, or pulseless electrical activity), resuscitation method, use of extracorporeal membrane oxygenation therapy, time to ROSC, GCS score within $24 \mathrm{~h}$ after ROSC, and APACHE II score within $24 \mathrm{~h}$ after ROSC.

2) Laboratory indicators: all indicators were collected $0-24 \mathrm{~h}$ before cardiac arrest and $0-72 \mathrm{~h}$ after ROSC (0-12, 12-24, 24-48, and 48-72 h), including lactate (Lac), albumin (Alb), total bilirubin (TB), creatinine $(\mathrm{Cr})$, hemoglobin $(\mathrm{Hb})$, mean platelet volume (MPV), red blood cell distribution width (RDW) and routine inflammatory markers. The routine inflammatory markers included absolute monocyte count (AMC), absolute lymphocyte count (ALC), absolute neutrophil count (ANC), white blood cell (WBC) count, platelet (PLT) count, neutrophil-lymphocyte ratio (NLR), platelet-lymphocyte ratio (PLR) and systemic immune-inflammation index (SII).

All the data were collected by two research assistants through the electronic medical record system. After data collection, the patient's name and medical record number were deleted, and the patient was given a unique study number. The statistical analyst reviewed all the data to confirm the accuracy and manually verified the incongruent or out-of-range values. Before statistical analysis, the data set was verified and cleaned up to prevent any further changes and ensure the consistency and integrity of the statistical records and analysis data. All the researchers who collected and collated the data were blinded to the research content.

\subsection{Definition of relevant variables}

\subsubsection{Clinical indicators}

All IHCA and CPR outcome reports complied with the Utstein style of reporting IHCA research [14]. Sustained ROSC was defined as a ROSC duration $\geq 20$ minutes without CPR. Time to ROSC was defined as the time from cardiac arrest to the first recording of sustained ROSC [17]. Pulmonary infection was 
defined according to the diagnostic criteria; clinicians made this diagnosis and uploaded it to the electronic case system to generate a code. In this study, the recorded diagnostic code was used to determine whether the patient had pulmonary infection before IHCA. The CCI was calculated according to the medical history of patients before IHCA [18]. The GCS score within $24 \mathrm{~h}$ after ROSC was used. If there were multiple scores, the lowest was selected. The APACHE II score within $24 \mathrm{~h}$ after ROSC was used. If there were multiple scores, the highest was selected [19].

\subsubsection{Laboratory indicators}

All laboratory indicators were tested by the laboratory of the First Affiliated Hospital of Chongqing Medical University, and test values were uploaded to the electronic medical record system. According to the time at which the blood samples were obtained, the test values were collected $0-24 \mathrm{~h}$ before IHCA and at $0-12,12-24,24-48$, and $48-72 \mathrm{~h}$ after ROSC. In this study, the normal reference values for relevant laboratory indicators were as follows: Lac: $0.5-2.2 \mathrm{mmol} / \mathrm{L} ;$ Alb $35-50 \mathrm{~g} / \mathrm{L} ; \mathrm{TB} 3-22 \mu \mathrm{mol} / \mathrm{L} ; \mathrm{Cr}$ : female 41-97 $\mu \mathrm{g} / \mathrm{L}$, male 57-106 $\mu \mathrm{g} / \mathrm{L} ; \mathrm{Hb} 130-175 \mathrm{~g} / \mathrm{L}$; MPV 7.6-13.2 fL; RDW 12\% - 16\%; AMC 0.10-

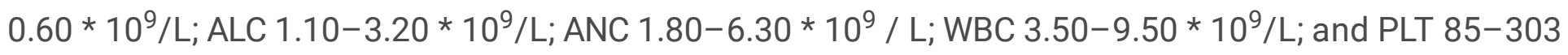
$* 10^{9} / \mathrm{L}$. Recently, increasing evidence has indicated that there are strong interactions not only between inflammatory factors but also between inflammatory factors and PLTs in the pathophysiological development of PCAS after CPR [20]. Therefore, this study included an analysis of relevant routine composite inflammatory markers, including the NLR, PLR and SII. The NLR, PLR and SIl values were calculated with the same blood sample from each patient, and the calculation formulas were as follows: NLR $=$ ANC $/$ ALC; PLR $=$ PLT $/$ ALC and SII $=$ PLT * NLR.

The classification cutoff values for continuous variables were as follows: age: 65 years old; $\mathrm{Cr}$ : the diagnostic value of our hospital; Lac: mean; PLR: median; and other continuous variables: median.

\subsection{Statistical analysis}

Categorical variables are expressed as rates $(n, \%)$. Continuous variables with a normal distribution are expressed as the mean \pm standard deviation (). Skewed continuous variables are expressed as the median and interquartile range (IQR). A linear mixed model was used to analyze the dynamic change trend of laboratory indicators of 85 patients within $72 \mathrm{~h}$ after ROSC. The repeated test values of AMC, ALC, ANC, WBC, PLT, NLR, PLR and SIl at 0-12 h, 12-24 h, 24-48 h, and 48-72 h after ROSC were regarded as time-dependent variables. Variables with $\mathrm{P}<0.05$ in the univariate Cox regression analysis were included in the multivariate Cox regression analysis, and multivariate Cox regression was used to identify the independent risk factors for 30-day mortality. Hazard ratios (HRs) and $95 \%$ confidence intervals (Cls) were used to assess the association of risk factors with 30-day mortality. Statistical analysis was performed using SAS 9.4. When the two-tailed $P$ value was $<0.05$, the difference was considered statistically significant.

\section{Results}




\subsection{Association of demographic, clinical and laboratory indicators before IHCA with 30-day mortality}

The association of demographic characteristics, clinical characteristics, and laboratory indicators before IHCA with 30-day mortality is shown in Table 1. A total of 85 patients with IHCA were included in this study. Of them, 54 patients died, and 31 survived during the 30-day follow-up. The 0-72h cumulative mortality was $25.88 \%$, the $0-30$ day cumulative mortality was $57.65 \%$, and the median survival time was 13.79 days. The mean age of IHCA patients was 61.41 years old, and $54.12 \%$ were male. Of the $85 \mathrm{IHCA}$ patients, $37.65 \%$ had cardiogenic causes, and noncardiogenic causes accounted for $62.35 \%$ of cases. 13 patients presented initial rhythm as ventricular fibrillation and ventricular tachycardia when IHCA occurred, and of them, 12 patients received CPR and an automated external defibrillator for resuscitation. Of the 85 patients, only 3 patients received the treatment of extracorporeal membrane oxygenation, and their 30 -day survival rate was $100 \%$. The median time to ROSC was 20 minutes, but it was not associated with 30-day mortality $(P>0.05)$. Age, $\mathrm{CCl}$, APACHE II score and $\mathrm{Cr}$ before IHCA were associated with 30day mortality (all $P<0.05$ ). Overall, $48.24 \%$ of patients had pulmonary infection before IHCA, but there was no association of inflammatory markers before IHCA with 30-day mortality $(P>0.05)$. 
Table 1

Association of demographic, clinical and laboratory indicators before IHCA with 30-day mortality.

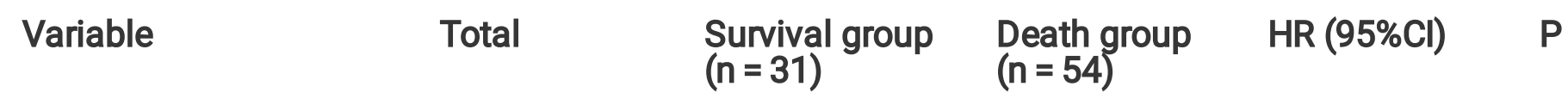

Baseline

characteristics

$\begin{array}{llllll}\text { Age } & 61.41 \pm & 56.03 \pm 21.2 & 64.5 \pm 17.52 & 1.016(1.002, & 0.028 \\ & 19.26 & & & 1.031)\end{array}$

Sex

$\begin{array}{llllll}\text { Male } & 46(54.12 \%) & 18(58.06 \%) & 28(51.85 \%) & \begin{array}{l}1.0 \\ \text { (reference) }\end{array} \\ \text { Female } & 39(45.88 \%) & 13(41.94 \%) & 26(48.15 \%) & \begin{array}{l}1.292(0.757, \\ 2.204)\end{array} & 0.348 \\ \mathrm{CCl} & 5(2,7) & 3(1,5) & 6(2,7) & \begin{array}{l}1.094(1.016, \\ 0.018\end{array}\end{array}$

Pulmonary infection

$\begin{array}{llllll}\text { No } & 44(51.76 \%) & 19(61.29 \%) & 25(46.30 \%) & \begin{array}{l}1.0 \\ \text { (reference) }\end{array} \\ \text { Yes } & 41(48.24 \%) & 12(38.71 \%) & 29(53.70 \%) & \begin{array}{l}1.396(0.818, \\ 2.385)\end{array} & 0.222 \\ & & & & \end{array}$

Etiology

Cardiogenic

$32(37.65 \%) \quad 10(32.26 \%)$

$22(40.74 \%)$

1.0

(reference)

Noncardiogenic

$53(62.35 \%) \quad 21(67.74 \%)$

$32(59.26 \%)$

$0.779(0.452$, 1.342)

Initial rhythm

ventricular tachycardia $\quad 5(5.88 \%)$

$2(6.45 \%)$

$3(5.56 \%)$

1.0

(reference)

ventricular

$8(9.41 \%)$

$2(6.45 \%)$

$6(11.11 \%)$

$1.444(0.381$, $5.465)$

fibrillation

Asystole

$38(44.71 \%) \quad 9(29.03)$

$29(53.70)$

$1.798(0.577, \quad 0.312$
$5.605)$

Note: $\mathrm{CCl}=$ Charlson comorbidity index; $\mathrm{CPR}=$ Cardiopulmonary resuscitation; $\mathrm{AED}=$ Automated external defibrillator; $\mathrm{ECMO}=$ Extracorporeal membrane oxygenation; $\mathrm{ROSC}=$ Recovery of spontaneous circulation; GCS = Glasgow coma score; Lac = Lactate; Alb = Albumin; TB = Total bilirubin; $\mathrm{Cr}=$ Creatinine; $\mathrm{Hb}=$ Hemoglobin; $\mathrm{MPV}=$ Mean platelet volume; $\mathrm{RDW}=$ Red blood cell distribution width; $\mathrm{AMC}=$ Absolute monocyte count; $\mathrm{ALC}=$ Absolute lymphocyte count; $\mathrm{ANC}=$ Absolute neutrophil count; $\mathrm{WBC}=$ White blood cell; PLT = Platelet; NLR = Neutrophil-lymphocyte ratio; PLR = Platelet-lymphocyte ratio; SII = Systemic immune-inflammation index. 


\begin{tabular}{|c|c|c|c|c|c|}
\hline Variable & Total & $\begin{array}{l}\text { Survival group } \\
(n=31)\end{array}$ & $\begin{array}{l}\text { Death group } \\
(n=54)\end{array}$ & $\mathrm{HR}(95 \% \mathrm{Cl})$ & $P$ \\
\hline Bradycardia & $28(32.94 \%)$ & $15(48.39 \%)$ & $13(24.07 \%)$ & $\begin{array}{l}0.746(0.223 \\
2.491)\end{array}$ & 0.634 \\
\hline $\begin{array}{l}\text { pulseless electrical } \\
\text { activity }\end{array}$ & $6(7.06 \%)$ & $3(9.68 \%)$ & $3(5.56 \%)$ & $\begin{array}{l}0.773(0.17 \\
3.522)\end{array}$ & 0.739 \\
\hline \multicolumn{6}{|c|}{ Resuscitation method } \\
\hline CPR & 73 (85.88\%) & $25(80.65 \%)$ & 48 (88.89) & $\begin{array}{l}1.0 \\
\text { (reference) }\end{array}$ & \\
\hline CPR + AED & $12(14.12 \%)$ & $6(19.35 \%)$ & $6(11.11 \%)$ & $\begin{array}{l}0.707(0.302, \\
1.653)\end{array}$ & 0.423 \\
\hline \multicolumn{6}{|l|}{ Use of ECMO } \\
\hline No & $82(96.47 \%)$ & $28(90.32 \%)$ & $54(100.00 \%)$ & $\begin{array}{l}1.0 \\
\text { (reference) }\end{array}$ & \\
\hline Yes & $3(3.53 \%)$ & $3(9.68 \%)$ & $0(0.00 \%)$ & $\begin{array}{l}0.157(0.009 \\
2.616)\end{array}$ & 0.197 \\
\hline Time to ROSC & $20(10,35)$ & $20(7,30)$ & $21.5(13,40)$ & $\begin{array}{l}1.008(0.997, \\
1.019)\end{array}$ & 0.169 \\
\hline GCS score & $3(3,6)$ & $5(3,8)$ & $3(3,5)$ & $\begin{array}{l}0.906(0.82 \\
1.002)\end{array}$ & 0.055 \\
\hline APACHE II score & $26(18,32)$ & $22(13,26)$ & $28.5(22,34)$ & $\begin{array}{l}1.029(1.011 \\
1.046)\end{array}$ & 0.001 \\
\hline \multicolumn{6}{|l|}{$\begin{array}{l}\text { Laboratory indicators } \\
\text { before IHCA }\end{array}$} \\
\hline Lac & $2.3(1.1,4.3)$ & $1.93(1,3.8)$ & $\begin{array}{l}2.55(1.25 \\
4.6)\end{array}$ & $\begin{array}{l}1.087(0.999 \\
1.184)\end{array}$ & 0.054 \\
\hline Alb & $35(32,38)$ & $33(31,38)$ & $35(33,39)$ & $\begin{array}{l}1.005(0.97 \\
1.042)\end{array}$ & 0.772 \\
\hline TB & $12.2(8,17.3)$ & $11.4(8.2,15.8)$ & $\begin{array}{l}12.55(7.7 \\
19.8)\end{array}$ & $\begin{array}{l}1.011(0.998, \\
1.025)\end{array}$ & 0.090 \\
\hline $\mathrm{Cr}$ & $71(58,116)$ & $61(51,87)$ & $\begin{array}{l}86.5(64, \\
130)\end{array}$ & $\begin{array}{l}1.002(1 \\
1.004)\end{array}$ & 0.017 \\
\hline
\end{tabular}

Note: $\mathrm{CCl}=$ Charlson comorbidity index; $\mathrm{CPR}=$ Cardiopulmonary resuscitation; $\mathrm{AED}=$ Automated external defibrillator; $\mathrm{ECMO}=$ Extracorporeal membrane oxygenation; ROSC = Recovery of spontaneous circulation; GCS = Glasgow coma score; Lac = Lactate; Alb = Albumin; TB = Total bilirubin; $\mathrm{Cr}=$ Creatinine; $\mathrm{Hb}=$ Hemoglobin; $\mathrm{MPV}=$ Mean platelet volume; $\mathrm{RDW}=$ Red blood cell distribution width; $A M C=$ Absolute monocyte count; $A L C=$ Absolute lymphocyte count; $A N C=$ Absolute neutrophil count; $\mathrm{WBC}=$ White blood cell; PLT = Platelet; NLR = Neutrophil-lymphocyte ratio; PLR = Platelet-lymphocyte ratio; SII = Systemic immune-inflammation index. 


\begin{tabular}{|c|c|c|c|c|c|}
\hline Variable & Total & $\begin{array}{l}\text { Survival group } \\
(\mathrm{n}=31)\end{array}$ & $\begin{array}{l}\text { Death group } \\
(n=54)\end{array}$ & HR (95\%Cl) & $P$ \\
\hline $\mathrm{Hb}$ & $\begin{array}{l}106.12 \pm \\
26.57\end{array}$ & $105.77 \pm 30.19$ & $\begin{array}{l}106.31 \pm \\
24.55\end{array}$ & $\begin{array}{l}0.999(0.989 \\
1.009)\end{array}$ & 0.837 \\
\hline MPV & $\begin{array}{l}11(10.2 \\
11.8)\end{array}$ & $11(10.2,11.9)$ & $\begin{array}{l}11.15(10.2, \\
11.8)\end{array}$ & $\begin{array}{l}1.005(0.988 \\
1.023\end{array}$ & 0.575 \\
\hline RDW & $\begin{array}{l}14.3(13.2 \\
15.8)\end{array}$ & $14(13.1,15.3)$ & $\begin{array}{l}\text { 14.6 (13.4, } \\
16.3)\end{array}$ & $\begin{array}{l}1.134(0.986, \\
1.304)\end{array}$ & 0.078 \\
\hline AMC & $\begin{array}{l}0.53(0.35 \\
0.86)\end{array}$ & $\begin{array}{l}0.48(0.35 \\
0.86)\end{array}$ & $\begin{array}{l}0.53(0.35 \\
0.86)\end{array}$ & $\begin{array}{l}1.116(0.666 \\
\sim 1.87)\end{array}$ & 0.676 \\
\hline ALC & $\begin{array}{l}0.87(0.56 \\
1.33)\end{array}$ & $\begin{array}{l}0.95(0.73, \\
1.46)\end{array}$ & $\begin{array}{l}0.87(0.52, \\
1.29)\end{array}$ & $\begin{array}{l}0.749(0.451 \\
1.243)\end{array}$ & 0.264 \\
\hline ANC & $\begin{array}{l}7.58(4.81 \\
10.49)\end{array}$ & $\begin{array}{l}7.9(4.81 \\
10.31)\end{array}$ & $\begin{array}{l}7.45(4.66 \\
10.54)\end{array}$ & $\begin{array}{l}1.002(0.94, \\
1.069)\end{array}$ & 0.943 \\
\hline WBC & $9.86 \pm 4.69$ & $9.8 \pm 3.6$ & $9.89 \pm 5.24$ & $\begin{array}{l}0.992 \\
1.055)\end{array}$ & 0.801 \\
\hline PLT & $\begin{array}{l}185(127 \\
272)\end{array}$ & $208(146,302)$ & $\begin{array}{l}167(107, \\
272)\end{array}$ & $\begin{array}{l}0.999(0.996 \\
1.001)\end{array}$ & 0.349 \\
\hline NLR & $\begin{array}{l}8.24(4.95 \\
13.24)\end{array}$ & $\begin{array}{l}8.36(3.59 \\
14.5)\end{array}$ & $\begin{array}{l}8.09(5.07 \\
13.24)\end{array}$ & $\begin{array}{l}1.016(0.987 \\
1.047)\end{array}$ & 0.287 \\
\hline PLR & $\begin{array}{l}19.64(13.95 \\
35.63)\end{array}$ & $\begin{array}{l}18.8(15.25, \\
32.74)\end{array}$ & $\begin{array}{l}19.82(12.64 \\
42.45)\end{array}$ & $\begin{array}{l}1.005(0.993 \\
1.017)\end{array}$ & 0.423 \\
\hline SII & $\begin{array}{l}14.46(8.12 \\
29.61)\end{array}$ & $\begin{array}{l}14.55(8.12, \\
29.61)\end{array}$ & $\begin{array}{l}14.15(6.88, \\
31.57)\end{array}$ & $\begin{array}{l}1.005(0.993 \\
1.018)\end{array}$ & 0.401 \\
\hline \multicolumn{6}{|c|}{ 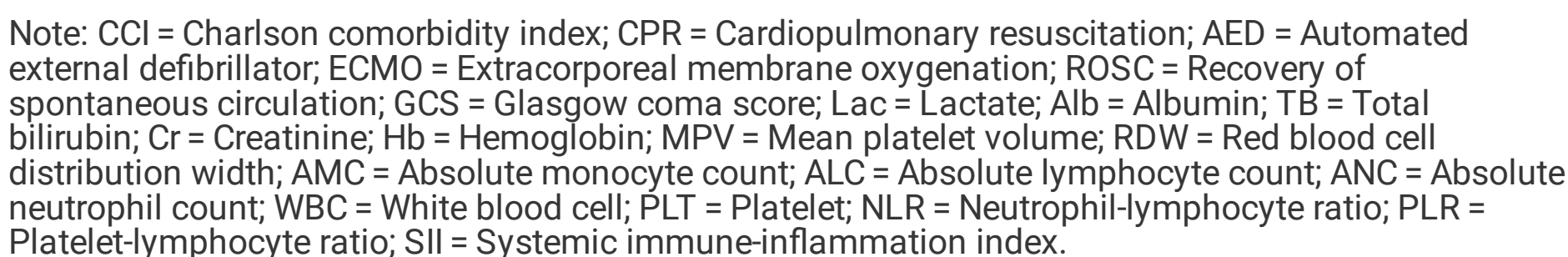 } \\
\hline
\end{tabular}

3.2 The dynamic change trends of laboratory indicators within $72 \mathrm{~h}$ after ROSC and its association with 30-day mortality

The repeated test values of laboratory indicators of 85 IHCA patients at $0-12 h, 12-24 h, 24-48 \mathrm{~h}$, and 48-72 $\mathrm{h}$ after ROSC were regarded as time-dependent variables. The analysis results of the dynamic change trends are shown in Appendix 1 . The differences in inflammatory markers (AMC, ALC, ANC, WBC count, PLT count, NLR, PLR and SII) at different periods within $72 \mathrm{~h}$ after ROSC were statistically significant (all $P<0.05)$.

The dynamic change trends of inflammatory markers with time are shown in Fig. 2. Within $72 \mathrm{~h}$ after ROSC, the AMC showed no significant change trend (Fig. 2A), the ALC showed an overall upward trend 
(Fig. 2B), and the ANC, WBC, PLT, NLR, PLR and SIl showed an overall downward trend (Fig. 2C-H); in addition, the PLR and SII tended to be stable with time.

Univariate Cox regression analysis based on time-dependent variables showed that of the laboratory indicators tested within $72 \mathrm{~h}$ after ROSC, Lac and PLR were associated with 30-day mortality (both $\mathrm{P}<$ 0.05), as shown in Table 2.

Table 2

Univariate analysis of the association of laboratory indicators measured within $72 \mathrm{~h}$ after ROSC with 30day mortality.

\begin{tabular}{|c|c|c|c|c|}
\hline Variable & $\beta$ & SE & $\mathrm{HR}(95 \% \mathrm{Cl})$ & $\mathbf{P}$ \\
\hline $\operatorname{Lac}(<8$ vs $\geq 8)$ & 0.050 & 0.025 & $1.052(1.002,1.104)$ & 0.042 \\
\hline Alb $(<30$ vs $\geq 30)$ & -0.015 & 0.336 & $0.985(0.510,1.903)$ & 0.965 \\
\hline TB (<14.5 vs $\geq 14.5)$ & 0.414 & 0.338 & $1.513(0.779,2.936)$ & 0.221 \\
\hline $\operatorname{Cr}(<130$ vs $\geq 130)$ & 0.530 & 0.336 & $1.700(0.879,3.285)$ & 0.115 \\
\hline $\mathrm{Hb}(<100$ vs $\geq 100)$ & -0.306 & 0.338 & $0.736(0.379,1.429)$ & 0.365 \\
\hline $\operatorname{MPV}(<11.2$ vs $\geq 11.2)$ & -0.275 & 0.336 & $0.760(0.393,1.467)$ & 0.413 \\
\hline $\operatorname{RDW}(<14.8$ vs $\geq 14.8)$ & 0.435 & 0.338 & $1.545(0.796,2.999)$ & 0.198 \\
\hline $\operatorname{AMC}(<0.56$ vs $\geq 0.56)$ & 0.092 & 0.334 & $1.096(0.569,2.111)$ & 0.783 \\
\hline $\operatorname{ALC}(<0.84$ vs $\geq 0.84)$ & -0.462 & 0.337 & $0.630(0.326,1.220)$ & 0.171 \\
\hline ANC $(<12$ vs $\geq 12)$ & 0.004 & 0.350 & $1.004(0.505,1.994)$ & 0.992 \\
\hline WBC $(<14$ vs $\geq 14)$ & 0.363 & 0.340 & $1.437(0.738,2.797)$ & 0.286 \\
\hline PLT (> 150 vs $\leq 150)$ & -0.495 & 0.364 & $0.610(0.299,1.243)$ & 0.174 \\
\hline $\operatorname{NLR}(<13$ vs $\geq 13)$ & 0.524 & 0.336 & $1.689(0.874,3.263)$ & 0.119 \\
\hline $\operatorname{PLR}(<180$ vs $\geq 180)$ & 0.699 & 0.339 & $2.012(1.035,3.911)$ & 0.039 \\
\hline SII (< 1900 vs $\geq 1900)$ & 0.574 & 0.338 & $1.775(0.915,3.446)$ & 0.090 \\
\hline \multicolumn{5}{|c|}{$\begin{array}{l}\text { Note: Lac = Lactate; Alb = Albumin; } \mathrm{TB}=\text { Total bilirubin; } \mathrm{Cr}=\text { Creatinine; } \mathrm{Hb}=\text { Hemoglobin; } \mathrm{MPV}=\text { Mea } \\
\text { platelet volume; RDW = Red blood cell distribution width; } \mathrm{AMC}=\mathrm{Absolute} \text { monocyte count; } \mathrm{ALC}= \\
\text { Absolute lymphocyte count; ANC = Absolute neutrophil count; } \mathrm{WBC}=\text { White blood cell; } \mathrm{PLT}=\text { Platelet; } \\
\text { NLR = Neutrophil-lymphocyte ratio; PLR = Platelet-lymphocyte ratio; SII = Systemic immune- } \\
\text { inflammation index. }\end{array}$} \\
\hline
\end{tabular}

\subsection{Multivariate analysis of 30-day mortality}


The variables with $\mathrm{P}<0.05$ in the univariate analysis were included in multivariate analysis: including age, CCl, APACHE II, Cr before IHCA, Lac within $72 \mathrm{~h}$ after ROSC and PLR within $72 \mathrm{~h}$ after ROSC (all $\mathrm{P}<$ 0.05) (Tables 1 and 2). After adjusting for confounding variables in the Cox multivariate regression analysis, the multivariate results showed that PLR $\geq 180$ had a $199.3 \%$ increased risk of 30 -day mortality in IHCA patients $(\mathrm{HR}=2.993,95 \% \mathrm{Cl}(1.442,6.214))$. IHCA patients with a $\mathrm{CCl} \geq 5$ had a $136.6 \%$ increased risk of 30-day mortality $(\mathrm{HR}=2.366,95 \% \mathrm{Cl}(1.084,5.168))$. When APACHE $I \geq 26$, the risk of 30-day mortality increased by $155 \%(\mathrm{HR}=2.550,95 \% \mathrm{Cl}(1.001,6.498))$. Abnormal $\mathrm{Cr}$ before IHCA increased the risk of 30-day mortality by $241.7 \%(\mathrm{HR}=3.417,95 \% \mathrm{Cl}(1.441,8.104))$ (Fig. 3).

\section{Discussion}

This case-control study included a total of 85 IHCA patients and retrospectively analyzed demographics, clinical characteristics and relevant laboratory indicators within $72 \mathrm{~h}$ after ROSC. The results of the linear mixed model showed that within $72 \mathrm{~h}$ after ROSC, inflammatory markers showed different patterns: the AMC showed no significant change trend, the ALC showed an overall upward trend, and the ANC, WBC, PLT, NLR, PLR and SII showed an overall downward trend. After adjusting for confounding variables by Cox multivariate regression, PLR within $72 \mathrm{~h}$ after ROSC was an independent risk factor for 30-day mortality in IHCA patients. When PLR $\geq 180$, the risk of 30-day mortality of IHCA patients increased by 199.3\% ( $\mathrm{HR}=2.993,95 \% \mathrm{Cl}(1.442,6.214))$. The inflammatory biomarker PLR can be used as a predictor of 30-day mortality in IHCA patients with ROSC, and it can be a reference for early prognostication.

Early organ failure is a main cause of short-term mortality in IHCA patients, and its potential pathological process is the development of PCAS. In particular, the comprehensive activation of the immune system and coagulation pathway within $72 \mathrm{~h}$ can lead to coagulation disorders and multiorgan failure and eventually to the death of patients. Many studies have pointed out that the systemic inflammatory response plays an important role in the pathophysiological development of early PCAS and affects the prognosis of IHCA patients $[6,12]$. Neutrophils are early determinants of the development of the systemic inflammatory response. Whole-body ischemia and reperfusion during CPR can activate neutrophils to release inflammatory mediators, such as elastase and heparin binding protein, which can lead to inflammatory tissue damage and therefore affect the prognosis of patients [21, 22]. Villois et al. [23] reported that a low ALC on admission is an independent predictor of poor prognosis in OHCA patients. In a large retrospective cohort study of $>1,000$ OHCA patients, Weiser et al. [24] further showed that NLR on admission was a predictor of long-term mortality of patients with cardiogenic OHCA. OHCA patients with NLR $\geq 6$ had a higher risk of mortality. Additionally, PLTs have been proven to play an important immune role in the systemic inflammatory response and have an important impact on the prognosis of patients $[20,25]$. Kim et al. [26] identified that a continuously decreased PLT count within 7 days is associated with a poor neurologic outcome and mortality at 6 months. Therefore, the early dynamic changes in routine inflammatory markers may reflect the immunopathological process of PCAS, which is closely 
related to the prognosis of cardiac arrest. Therefore, these dynamic changes could be used as an important index for prognosis assessment.

This study analyzed the dynamic changes of inflammatory markers within $72 \mathrm{~h}$ after ROSC in 85 IHCA patients, and found that the AMC trend did not significantly change, the ALC showed an overall upward trend, and the ANC, WBC count, PLT count, NLR, PLR and SIl showed an overall downward trend; in addition, the PLR and SII tended to be stable with time. Kim et al. [26] found that in OHCA patients treated with targeted temperature management, the PLT count continuously decreased within $72 \mathrm{~h}$ after cardiac arrest. Many recent studies on sepsis and other severe diseases [27-29] have shown that the NLR, PLR and SII can continue to decrease in the early stage of disease, which is consistent with the conclusion of our study. However, Ryzhov et al. [30] showed that the AMC increases briefly within $6 \mathrm{~h}$ after ROSC, the ALC shows a persistent decrease 6-72 $\mathrm{h}$ after ROSC, and the ANC and WBC count increase significantly within $48 \mathrm{~h}$ and $72-168 \mathrm{~h}$ after ROSC. These findings are inconsistent with the results of our study. First, these discrepancies can be explained by the heterogeneity of the study population; $80 \%$ of the patients had OHCA in Ryzhov's study [30], while the target population of our study was IHCA patients. In addition, the use of drugs in the early stage after cardiac arrest may affect the dynamic changes of related indicators; for example, corticosteroids can lead to lymphopenia after cardiac arrest [23]. Therefore, our study excluded patients using immunosuppressants, and these controversial results still need further verification.

Through analysis of the association of inflammatory markers within $72 \mathrm{~h}$ with prognosis, this study further found that only the PLR was associated with 30-day mortality. The PLR can be quickly calculated by obtaining the PLT count and ALC from routine clinical blood examinations. The PLR reveals changes in both the PLT count and the ALC caused by acute inflammation and a prethrombotic state. As a novel, simple and inexpensive routine composite inflammatory marker, the PLR has been proven to have value for predicting the prognosis of various disorders in recent years [31, 32]. A study on dynamic changes in the PLR in breast cancer patients identified that patients with a persistently low PLR after initial treatment have a significantly better prognosis in terms of late metastasis than other patients [31]. Shen et al. [33] showed that a high PLR on admission (PLR $>200$ ) was significantly associated with increased mortality in patients with sepsis $(\mathrm{OR}=1.0002,95 \% \mathrm{Cl}[1.0001-1.0004])$. Additionally, studies have also shown that a high PLR can be used to predict poor prognosis in relation to cardiovascular events [34]. In this study, when PLR $\geq 180$, the risk of 30-day mortality of IHCA patients increased by $199.3 \%$ (HR $=2.993,95 \% \mathrm{Cl}$ $(1.442,6.214))$. The reason for this pattern may be that PLTs play an important role in both the immunomodulatory and inflammatory processes in IHCA patients. They can contribute to the initiation or exacerbation of the inflammatory process by inducing the release of inflammatory cytokines and interacting with different kinds of bacteria and immune cells, including neutrophils, T lymphocytes, natural killer cells and macrophages. Higher PLT counts, to a certain extent, are associated with increased systemic inflammation [25], and a low ALC may represent a suppressed immune and inflammatory response $[28,35]$. Therefore, a higher PLR reflects a more severe systemic inflammatory immune response in IHCA patients, which is closely related to the development of PCAS and death. 
We acknowledge several limitations in our study. 1. This study is a single-center retrospective casecontrol study, and the sample size is relatively small, so it is necessary to verify the conclusions in a prospective study with an expanded sample size. 2 . Since $0-72 \mathrm{~h}$ after ROSC is an important period for determining the prognosis of patients, we focused on the association of the dynamic changes in inflammatory markers in this period with the 30-day mortality of IHCA patients to identify routine inflammatory markers that can predict prognosis early. However, according to the results of our study, the median survival time of patients was 13 days, so future studies should include routine inflammatory marker data after $72 \mathrm{~h}$ to provide a clearer picture of the progression of PCAS and the association of the change trends of inflammatory markers with mortality. 3. This study didn't conduct combined analysis of inflammatory markers. In a future study, we will combine related inflammatory markers, such as the PLR and NLR, to further explore the relationship between the severity of inflammation and the mortality of IHCA patients.

\section{Conclusions}

In conclusion, early identification of the risk factors for short-term mortality in IHCA patients and exploration of the dynamic changes in routine inflammatory markers can provide a reference for clinicians to determine patient prognosis early. The PLR is simple and inexpensive and can be used as an effective prognostic predictor of 30-day mortality in IHCA patients. As such, the PLR is worthy of further verification and promotion.

\section{Abbreviations}

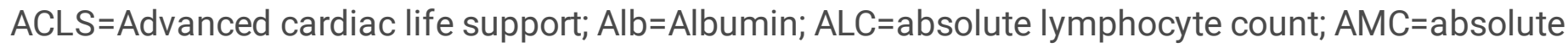
monocyte count; $\mathrm{ANC}=$ absolute neutrophil count; $\mathrm{CCl}=$ Charlson Comorbidity Index; $\mathrm{Cl}=$ confidence interval; $\mathrm{CPR}=$ Cardiopulmonary resuscitation; $\mathrm{Cr}=$ creatinine; $\mathrm{Hb}=$ hemoglobin; $\mathrm{HR}=\mathrm{Hazard}$ ratio; $\mathrm{IHCA}=$ in-hospital cardiac arrest; Lac=lactate; MPV=mean platelet volume; NLR=neutrophil-lymphocyte ratio; OHCA=outhospital cardiac arrest; PCAS=post cardiac arrest syndrome; PLR=platelet-lymphocyte ratio; PLT=platelet; $\mathrm{RDW}=$ red blood cell distribution width; ROSC=recovery of spontaneous circulation; TB=total bilirubin; $\mathrm{WBC}=$ white blood cell; SII=systemic immune-inflammation index .

\section{Declarations}

\section{Ethical approval and consent to participate}

All procedures performed in this study involving human participants were in accordance with the ethical standards of the institutional and/or national research committee and with the 1964 Helsinki Declaration and its later amendments or comparable ethical standards. 
All the coauthors have approved this version of the manuscript and consent to publication.

\section{Availability of data and materials}

The data that support the findings of this study are available from the corresponding author upon reasonable request.

\section{Competing interests}

The authors declare that they have no competing interests.

\section{Funding}

This study was sponsored by The National Natural Science Foundation of China. (number: 81801296)

\section{Authors' contributions}

Feng Li and Lihong Huang designed the study and performed the experiments; Jingjing Peng and Xuefeng Wang analyzed the data; Lihong Huang wrote the manuscript; Feng Li reviewed and edited the manuscript. All authors read and approved the final manuscript.

\section{Acknowledgements}

We thank all of the patients in this study for their cooperation.

\section{References}

1. Ofoma UR, Basnet S, Berger A, Kirchner HL, Girotra S. American Heart Association Get With the Guidelines - Resuscitation Investigators. Trends in survival after in-hospital cardiac arrest during nights and weekends. J Am Coll Cardiol. 2018;71:402-11.

2. Sandroni C, Nolan J, Cavallaro F, Antonelli M. In-hospital cardiac arrest: incidence, prognosis and possible measures to improve survival. Intensive Care Med. 2007;33:237-45.

3. Andersen LW, Holmberg MJ, Berg KM, Donnino MW, Granfeldt A. In-hospital cardiac arrest: a review. JAMA. 2019;321:1200-10.

4. Roberts BW, Kilgannon JH, Chansky ME, Mittal N, Wooden J, Parrillo JE, et al. Multiple organ dysfunction after return of spontaneous circulation in postcardiac arrest syndrome. Crit Care Med. 2013;41:1492-501.

5. Nolan JP, Neumar RW, Adrie C, Aibiki M, Berg RA, Bottiger BW, et al. Post-cardiac arrest syndrome: epidemiology, pathophysiology, treatment, and prognostication. A Scientific Statement from the International Liaison Committee on Resuscitation; the American Heart Association Emergency Cardiovascular Care Committee; the Council on Cardiovascular Surgery and Anesthesia; the Council on Cardiopulmonary, Perioperative, and Critical Care; the Council on Clinical Cardiology; the Council on Stroke. Resuscitation. 2008;79:350-79. 
6. Adrie C, Adib-Conquy M, Laurent I, Monchi M, Vinsonneau C, Fitting C, et al. Successful cardiopulmonary resuscitation after cardiac arrest as a "sepsis-like" syndrome. Circulation. 2002;106:562-8.

7. Spiel AO, Frossard M, Mayr FB, Kliegel A, Janata A, Uray T, et al. Pronounced platelet hyperfunction in patients with cardiac arrest achieving restoration of spontaneous circulation. Crit Care Med. 2009;37:975-9.

8. Stub D, Bernard S, Duffy SJ, Kaye DM. Post cardiac arrest syndrome: a review of therapeutic strategies. Circulation. 2011;123:1428-35.

9. Sugita A, Kinoshita K, Sakurai A, Chiba N, Yamaguchi J, Kuwana T, et al. Systemic impact on secondary brain aggravation due to ischemia/reperfusion injury in post-cardiac arrest syndrome: a prospective observational study using high-mobility group box 1 protein. Crit Care. 2017;21:247.

10. Patel JK, Sinha N, Hou W, Shah R, Qadeer A, Tran L, et al. Association of post-resuscitation inflammatory response with favorable neurologic outcomes in adults with in-hospital cardiac arrest. Resuscitation. 2021;159:54-9.

11. Czerwińska-Jelonkiewicz K, Grand J, Tavazzi G, Sans-Rosello J, Wood A, Oleksiak A, et al. Acute respiratory failure and inflammatory response after out-of-hospital cardiac arrest: results of the PostCardiac Arrest Syndrome (PCAS) pilot study. Eur Heart J Acute Cardiovasc Care. 2020;9:110-21.

12. Bro-Jeppesen J, Kjaergaard J, Wanscher M, Nielsen N, Friberg H, Bjerre M, et al. Systemic inflammatory response and potential prognostic implications after out-of-hospital cardiac arrest: a substudy of the target temperature management trial. Crit Care Med. 2015;43:1223-32.

13. Girotra S, Chan PS, Bradley SM. Post-resuscitation care following out-of-hospital and in-hospital cardiac arrest. Heart. 2015;101:1943-9.

14. Nolan JP, Berg RA, Andersen LW, Bhanji F, Chan PS, Donnino MW, et al. Cardiac arrest and cardiopulmonary resuscitation outcome reports: update of the utstein resuscitation registry template for in-hospital cardiac arrest: a consensus report from a task force of the international liaison committee on resuscitation (American Heart Association, European Resuscitation Council, Australian and New Zealand Council on Resuscitation, Heart and Stroke Foundation of Canada, InterAmerican Heart Foundation, Resuscitation Council of Southern Africa, Resuscitation Council of Asia). Circulation. 2019;140:e746-57.

15. Iqbal MB, Al-Hussaini A, Rosser G, Salehi S, Phylactou M, Rajakulasingham R, et al. Predictors of survival and favorable functional outcomes after an out-of-hospital cardiac arrest in patients systematically brought to a dedicated heart attack center (from the harefield cardiac arrest study). Am J Cardiol. 2015;115:730-7.

16. Morrison LJ, Neumar RW, Zimmerman JL, Link MS, Newby LK, McMullan PW, et al. Strategies for improving survival after in-hospital cardiac arrest in the United States: 2013 consensus recommendations: a consensus statement from the American Heart Association. Circulation. 2013;127:1538-63. 
17. Martinell L, Nielsen N, Herlitz J, Karlsson T, Horn J, Wise MP, et al. Early predictors of poor outcome after out-of-hospital cardiac arrest. Crit Care. 2017;21:96.

18. Oving I, van Dongen LHPI, Deurholt SC, Ramdani A, Beesems SG, Tan HL, et al. Comorbidity and survival in the pre-hospital and in-hospital phase after out-of-hospital cardiac arrest. Resuscitation. 2020;153:58-64.

19. Donnino MW, Salciccioli JD, Dejam A, Giberson T, Giberson B, Cristia C, et al. APACHE II scoring to predict outcome in post-cardiac arrest. Resuscitation. 2013;84:651-6.

20. Gando S, Wada T. Disseminated intravascular coagulation in cardiac arrest and resuscitation. J Thromb Haemost. 2019;17:1205-16.

21. Gando S, Tedo I. Increased neutrophil elastase release in patients with cardiopulmonary arrest: role of elastase inhibitor. Intensive Care Med. 1995;21:636-40.

22. Ristagno G, Masson S, Tiainen M, Bendel S, Bernasconi R, Varpula T, et al. Elevated plasma heparinbinding protein is associated with early death after resuscitation from cardiac arrest. Crit Care. 2016;20:251.

23. Villois P, Grimaldi D, Spadaro S, Shinotsuka CR, Fontana V, Scolletta S, et al. Lymphopaenia in cardiac arrest patients. Ann Intensive Care. 2017;7:85.

24. Weiser C, Schwameis M, Sterz F, Herkner H, Lang IM, Schwarzinger I, et al. Mortality in patients resuscitated from out-of-hospital cardiac arrest based on automated blood cell count and neutrophil lymphocyte ratio at admission. Resuscitation. 2017;116:49-55.

25. Gando S, Kameue T, Nanzaki S, Igarashi M, Nakanishi Y. Platelet activation with massive formation of thromboxane A 2 during and after cardiopulmonary resuscitation. Intensive Care Med. 1997;23:71-6.

26. Kim HJ, Park KN, Kim SH, Lee BK, Oh SH, Jeung KW, et al. Time course of platelet counts in relation to the neurologic outcome in patients undergoing targeted temperature management after cardiac arrest. Resuscitation. 2019;140:113-9.

27. Liu S, Li Y, She F, Zhao X, Yao Y. Predictive value of immune cell counts and neutrophil-to-lymphocyte ratio for 28-day mortality in patients with sepsis caused by intra-abdominal infection. Burns Trauma. 2021;9:tkaa040.

28. Zhao Q, Shen Y, Li R, Wu J, Lyu J, Jiang M, et al. Cardiac arrest and resuscitation activates the hypothalamic-pituitary-adrenal axis and results in severe immunosuppression. J Cereb Blood Flow Metab. 2020;41:1091-102.

29. Lin JX, Wang ZK, Huang YQ, Xie JW, Wang JB, Lu J, et al. Dynamic changes in pre- and postoperative levels of inflammatory markers and their effects on the prognosis of patients with gastric cancer. $J$ Gastrointest Surg. 2021;25:387-96.

30. Ryzhov S, May T, Dziodzio J, Emery IF, Lucas FL, Leclerc A, et al. Number of circulating CD 73expressing lymphocytes correlates with survival after cardiac arrest. J Am Heart Assoc. 2019;8:e010874. 
31. Kim JY, Jung EJ, Kim JM, Lee HS, Kwag SJ, Park JH, et al. Dynamic changes of neutrophil-tolymphocyte ratio and platelet-to-lymphocyte ratio predicts breast cancer prognosis. BMC Cancer. 2020;20:1206.

32. Condado JF, Junpaparp P, Binongo JN, Lasanajak Y, Witzke-Sanz CF, Devireddy C, et al. Neutrophillymphocyte ratio (NLR) and platelet-lymphocyte ratio (PLR) can risk stratify patients in transcatheter aortic-valve replacement (TAVR). Int J Cardiol. 2016;223:444-9.

33. Shen $Y$, Huang $X$, Zhang W. Platelet-to-lymphocyte ratio as a prognostic predictor of mortality for sepsis: interaction effect with disease severity-a retrospective study. BMJ Open. 2019;9:e022896.

34. Balta S, Ozturk $C$. The platelet-lymphocyte ratio: a simple, inexpensive and rapid prognostic marker for cardiovascular events. Platelets. 2014;26:680-1.

35. Grimaldi D, Louis S, Pène F, Sirgo G, Rousseau C, Claessens YE, et al. Profound and persistent decrease of circulating dendritic cells is associated with ICU-acquired infection in patients with septic shock. Intensive Care Med. 2011;37:1438-46.

\section{Figures}




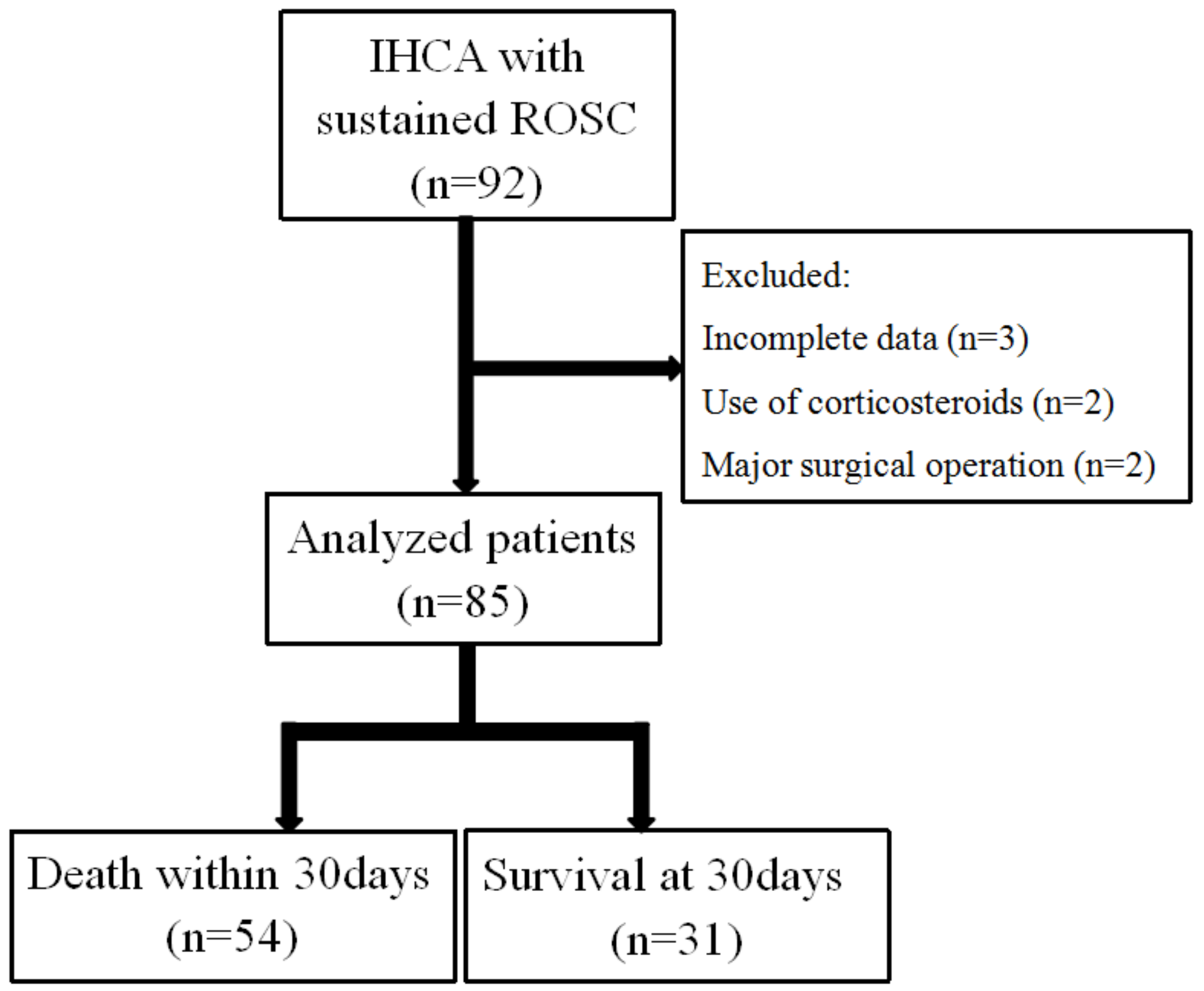

Figure 1

Flow Chart. 

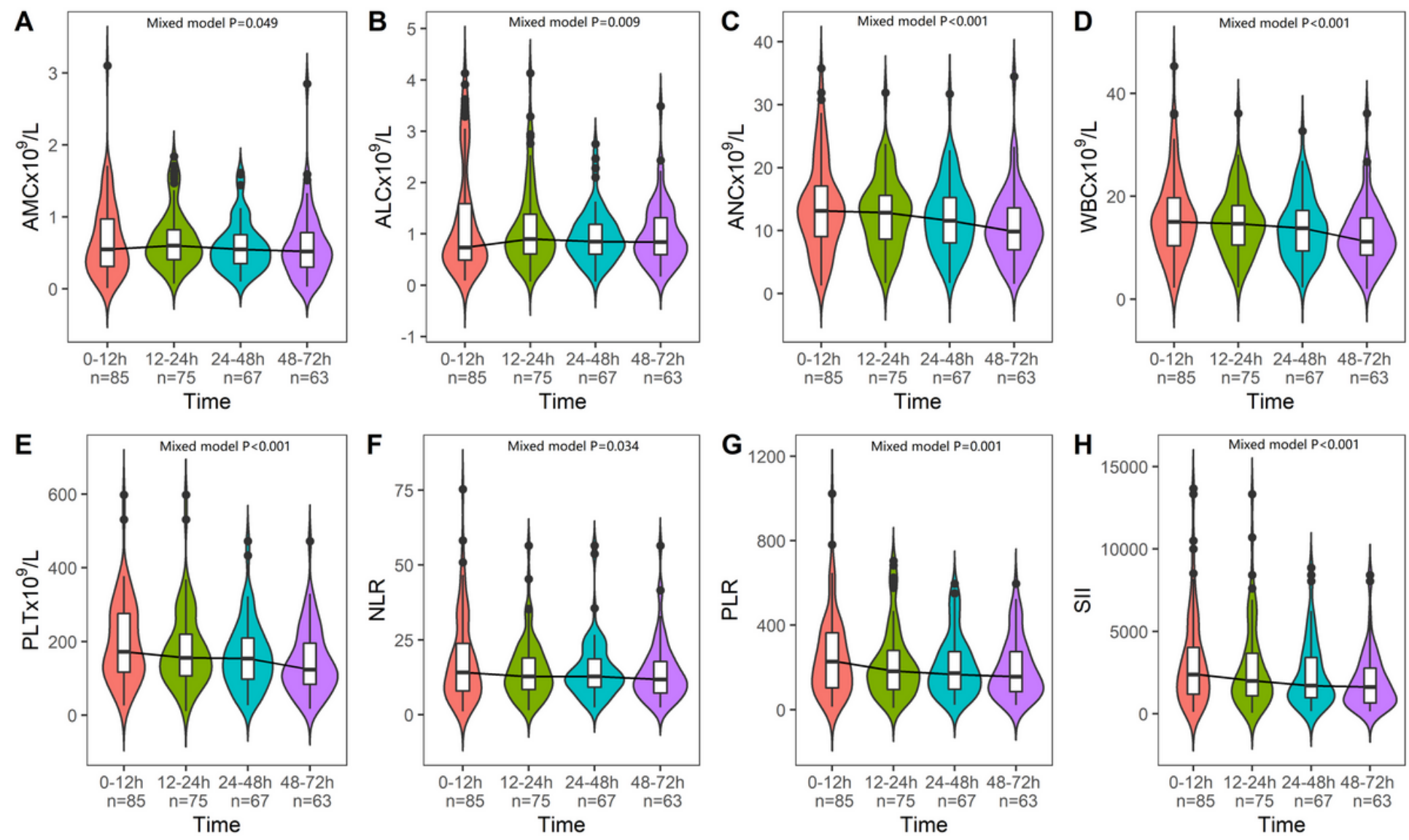

Figure 2

The dynamic change trends of inflammatory markers within $72 \mathrm{~h}$ after ROSC. AMC=Absolute monocyte

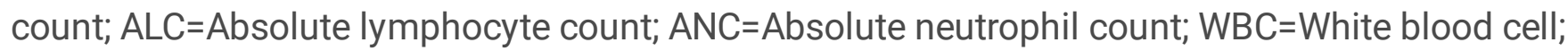
PLT=Platelet; NLR= Neutrophil-lymphocyte ratio; PLR=Platelet-lymphocyte ratio; SII=Systemic immuneinflammation index. 
Variables

$\mathrm{HR}(95 \% \mathrm{Cl})$

P

Age $(<65$ vs. $\geq 65$, years)

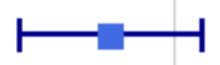

$0.550(0.234,1.292)$

0.170

$\mathrm{Cr}$ (Normal vs. Abnormal)

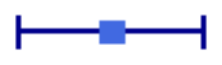

$3.417(1.441,8.104)$

0.005

$\mathrm{Lac}(<8 \mathrm{vs} . \geq 8, \mathrm{mmol} / \mathrm{L})$

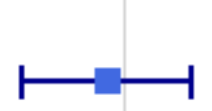

$0.858(0.390,1.888)$

0.703

$\mathrm{CCl}(5<$ vs. $\geq 5)$

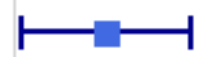

2.366(1.084,5.168)

0.031

APACHE( $<26$ vs. $\geq 26$ )

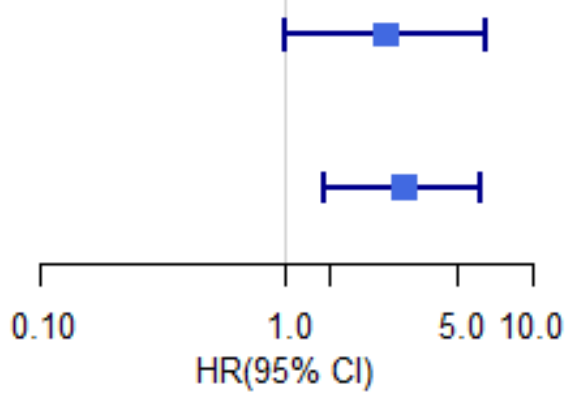

$2.550(1.001,6.498)$

0.049

PLR( $<180$ vs. $\geq 180$ )

$2.993(1.442,6.214) \quad 0.003$

\section{Figure 3}

Risk factors for 30-day mortality in the multivariate Cox regression model with time-dependent variables. Lac=Lactate; $\mathrm{Cr}=$ creatinine; $\mathrm{CCl}=$ Charlson comorbidity index; $\mathrm{PLR}=$ platelet-lymphocyte ratio.

\section{Supplementary Files}

This is a list of supplementary files associated with this preprint. Click to download.

- Appendix.docx 